\title{
Knowledge, Attitude and Clinical Decision-Making Abilities of Pediatric Nurses Regarding Pain Management
}

\author{
Nesrin Sen Celasin ${ }^{1} \mathbb{D}$, Sadiye Dur ${ }^{\mathbb{D}}$, Dilek $\operatorname{Ergin}^{1}$ (D), Duygu Karaarslan² ${ }^{(\mathbb{D})}$ \\ ${ }^{1}$ Manisa Celal Bayar University, Faculty of Health Sciences, Division of Nursing, Department of Pediatric Nursing, Manisa, Turkey. \\ ${ }^{2}$ Istanbul University, Florence Nightingale Faculty of Nursing, Department of Pediatric Nursing, Istanbul, Turkey. \\ Correspondence Author: Nesrin Sen Celasin \\ E-mail: nessen_72@yahoo.com
}

Received: $03.01 .2020 \quad$ Accepted: 14.08 .2020

\begin{abstract}
Objective: The aim of this study was to describe knowledge, attitude and clinical decision-making abilities of pediatric nurses regarding pain management, and to find the factors that affect them.

Methods: In this descriptive and analytical study, the participants consisted of 131 pediatric nurses who were employed in pediatric clinics of a university hospital and a state hospital in Manisa, Turkey. Data were collected by using the Nurse Description Form, the Questionnaire on Nurses' Attitudes and Knowledge About Pain, and the Clinical Decision Making Questionnaire.

Results: In the study, the mean (standard deviation) score of knowledge and attitude of pediatric nurses in pain management and patients with pain was $7.32(7.00)$, and the scores of $45 \%$ of them were at an intermediate level. It was found that while variables such as age, occupation and years of working experience did not affect the total mean score of knowledge and attitude of pediatric nurses in pain management, educational background and the unit at which they worked affected it. Moreover, most of the pediatric nurses had sufficient information regarding pain diagnosis; $61.1 \%$ of them observed patients' behavior while diagnosing the severity of pain, and $65.6 \%$ of them used a pain diagnosis scale to measure patients' pain.
\end{abstract}

Conclusion: As a result of the study, it was found that pediatric nurses had an intermediate level of knowledge and behavior regarding pain management and had sufficient knowledge about pain diagnosis and management.

Keywords: Attitude, clinical decision-making, knowledge, pain, pediatric nursing

\section{INTRODUCTION}

The concept of pain, which is considered not only a symptom of a certain disease but also an independent phenomenon, is defined as the fifth vital sign by the American Pain Society (APS). Pain is expressed as a concept which affects every age group, is individual and whose interpretation is subjective and universal $(1,2)$. Pain is an important factor in children's lives and is usually experienced for the first time during childhood. The American Academy of Pediatrics (AAP) and the APS suggest that pain and stress should be eased and minimized even in minor interventions like establishing vascular access (3-5).

Neurobiological development, age, previous experience of pain, learning status, gender, culture, personality structure, emotional state (fear, anxiety, depression), reactions of family members and healthcare professionals, and socio-cultural factors have an effect on pain perception. Particularly, the most important factor in children's pain perception and in their reaction to pain is their age. Children in different age groups have different pain perceptions and reactions $(6,7)$.
In pain management, pharmacological (anesthetics, analgesics and drugs) and non-pharmacological methods (such as position, giving a baby a pacifier, kangaroo care, massage, breastfeeding, reducing environmental stimuli, sucrose, music, guided imagery, hypnosis, breathing techniques and relactation, blowing up a balloon and coughing) are used $(6,8,9)$. Prevention and management of pain in children increase child's tolerance towards pain in subsequent applications (7). It is indicated that the effects of children's previous pain experiences continue into adulthood, and this may cause an increased reaction to pain and the avoidance of subsequent medical operations (10). It is important to diagnose children's pain correctly and timely for effective pain management (8). A multidisciplinary team approach is necessary to achieve success in pain management in children. A nurse is an important member of this team; a nurse's taking an active role in pain management starts with assessment and treatment of pain, choosing suitable interventions and planning caring $(8,11)$.

The most important difference that separates nurses from other team members in pain management is that they spend a long time with the patient, learn about the patient's 
previous pain experiences and methods of overcoming pain, and make use of this information if necessary. They also apply planned treatment, and observe the effects and results of the treatment $(6,12,13)$. Previous studies have shown that nurses' decisions in pain management and pain problems are more influenced by their own attitudes towards pain and their misperceptions of pain than by diagnosing patients' current conditions $(11,14)$. This study aims to determine the knowledge, attitude and clinical decision-making abilities of Turkish pediatric nurses regarding pain management, and to find the factors affecting them.

\section{METHODS}

\subsection{Study Design and Participants}

This study had a descriptive and analytical design and the study population included 170 pediatric nurses who were employed in pediatric clinics of a university hospital and a state hospital in Manisa, Turkey. No sampling method was used in the study and all the nurses $(n=131)$ were contacted within working hours and who accepted to take part in the research between these dates were included in the study. Of the nurses $77 \%$ were contacted. The nurses who declined to take part in the research $(n=19)$, who were on leave $(n=12)$, or had a sick leave $(n=8)$ were excluded.

\subsection{Data Collection}

Data was obtained by face-to-face interviews using the questionnaire forms, namely "Nurse Description Form", "Questionnaire on Nurses' Knowledge and Attitudes about Pain" and "Questionnaire on Clinical Decision-Making About Pain". The data collection forms were filled out by the nurses themselves. The completion of the data collection forms took 15 to 20 minutes.

\subsubsection{Questionnaires}

\subsubsection{Nurse Description Form}

This form includes 5 questions about the nurses' age, educational background, place of work, position/duty and years of work. This measure was prepared by the researchers.

\subsubsection{Questionnaire on Nurses' Knowledge and Attitude About Pain}

This questionnaire was formed on the basis of studies conducted to analyse the knowledge and attitude of nurses about pain management and patients with pain $(15,16)$. This questionnaire form was prepared by Özer et al. (11) and comprised of 16 True/False questions. Every 'True' response scored 1 point and every 'False' response scored 0 points. The lowest possible score on the questionnaire was 0 , and the highest was 16 . The highest score shows that a nurse's knowledge and attitude about pain is at the top level.

\subsubsection{Questionnaire on Clinical Decision-Making About Pain}

The Questionnaire on Clinical Decision-Making About Pain was formed by McCaffery and Ferrell (15) with the aim of determining nurses' clinical decision-making status about pain, and it were adapted to Turkish by Özer et al. (11). This questionnaire consists of 14 questions answered as 'Yes / No'.

\subsection{Statistical Analyses}

The findings were analysed using frequency [number (percentage)] distribution, mean, Kruskall-Wallis and Chi-Square tests. Descriptive statistics in the form of frequency and percentage were used to summarize nurses' descriptive features analyzing their answers given to the 'Questionnaire on Nurses' Knowledge and Attitude About Pain' and distribution of nurses' average knowledge and attitude scores about pain management. Kruskall-Wallis test was used to compare nurses' descriptive features (age, educational background, place of work, position/duty, years of work) and their total mean scores of knowledge and attitude about pain management. Mann Whitney $U$ test was used for determining the group causing the differentiation. In addition, Chi-square test was used to analyze the distribution of pediatric nurses by their use of a pain scale and their recording of pain according to the unit where they worked. Data were analyzed with the Statistical Package for the Social Sciences (SPSS Statistics for Windows, Version 23.0, IBM Corp., Armonk, NY). All the $p$-values that were $<0.05$ were considered to be statistically significant.

\subsection{Ethical Considerations}

For this study, approval was obtained from the Ethical Committee of Celal Bayar University Medical Faculty (Date/ IRB No: 25.03.2015/ 20.478.486-148). The survey was conducted in accordance with the Helsinki Declaration criteria. Written permissions from the institutions where the study would be conducted were taken. Before the data collection process, the participants were informed about the study and written informed consent was obtained from all subjects who agreed to participate in the study.

\section{RESULTS}

\subsection{Findings About Descriptive Characteristics of Pediatric Nurses}

Ages of 131 pediatric nurses participating in the study varied from 19 to 52 years, with a mean of $29.96 \pm 6.47$ years, and their professional experience varied from 1 to 20 years, with a mean of $7.37 \pm 5.54$ years. Of the pediatric nurses who took part in the research, $55.7 \%$ were between the ages of 21 and $30,69.5 \%$ of them had a Bachelor's Degree. It has been determined that $40.5 \%$ of the nurses were working in the Pediatric Unit, 55\% of them were working as a Clinical Nurse and $38.9 \%$ of them had professional experience between 6-10 years (Table 1 ). 
Table 1. Descriptive characteristics of pediatric nurses ( $n=131)$

\begin{tabular}{|c|c|c|c|}
\hline \multicolumn{2}{|l|}{ Characteristics } & $n$ & $\%$ \\
\hline \multirow[t]{5}{*}{ Age } & Less than 21 years & 4 & 3.1 \\
\hline & $21-30$ years & 73 & 55.7 \\
\hline & $31-40$ years & 48 & 36.6 \\
\hline & $41-50$ years & 5 & 3.8 \\
\hline & More than 50 years & 1 & 0.8 \\
\hline \multirow[t]{4}{*}{ Education } & Health Vocational High School & 14 & 10.7 \\
\hline & Associate Degree & 14 & 10.7 \\
\hline & Bachelor's Degree & 91 & 69.5 \\
\hline & Master's Degree & 12 & 9.2 \\
\hline \multirow[t]{4}{*}{ Place of Work } & Pediatric Unit & 53 & 40.5 \\
\hline & Pediatric Surgery Unit & 14 & 10.7 \\
\hline & Neonatal Intensive Care Unit & 17 & 35.9 \\
\hline & Pediatric Emergency Unit & 47 & 13.0 \\
\hline \multirow[t]{4}{*}{ Position/Duty } & Clinical Nurse & 72 & 55.0 \\
\hline & Intensive Care Nurse & 43 & 32.8 \\
\hline & Executive Nurse & 7 & 5.3 \\
\hline & Outpatient Clinic Nurse & 9 & 6.9 \\
\hline \multirow[t]{4}{*}{ Years of Work } & Less than 5 years & 45 & 34.4 \\
\hline & $6-10$ years & 51 & 38.9 \\
\hline & $11-15$ years & 20 & 15.3 \\
\hline & More than 15 years & 15 & 11.5 \\
\hline
\end{tabular}

\subsection{Findings on Pediatric Nurses' Knowledge and Attitude Scores in Pain Management}

When examining the responses of pediatric nurses to the 'Questionnaire on Knowledge and Attitude About Pain', it was determined that the questions with most frequent correct answers were the $10^{\text {th }}, 14^{\text {th }}$ and $5^{\text {th }}$ questions, and the questions with most frequent wrong answers were the $13^{\text {th }}$, $16^{\text {th }}$ and $9^{\text {th }}$ questions (Table 2).

When the responses given to these questions were evaluated (with a total possible score of 16), it was found that the knowledge and attitude scores of $45.0 \%$ of the pediatric nurses about pain management and patients with pain was at a mid-level (Table 3).

When the nurses were asked the question 'How much do you trust yourself about the accuracy of the questions answered in the Knowledge and Attitude About Pain Questionnaire?', $61.8 \%$ of the nurses marked number 4 and $29.8 \%$ marked number 3 on a scale where 1 stood for 'I don't trust myself' and 5 stood for 'I trust myself'. It was found in the research that the average self-reliance score for all the nurses was $3.74 \pm 0.60(\min =2, \max =5)$.

Table 2. Answers given by pediatric nurses to the questionnaire on knowledge and attitude about pain*

\begin{tabular}{|l|c|c|c|c|}
\hline $\begin{array}{l}\text { Questions and answer key on the } \\
\text { questionnaire form }\end{array}$ & \multicolumn{2}{|c|}{$\begin{array}{c}\text { True } \\
\text { answer }\end{array}$} & \multicolumn{2}{|c|}{$\begin{array}{c}\text { False } \\
\text { answer }\end{array}$} \\
\hline 1. Observed changes in vital signs are & 40 & 30.5 & 91 & 69.5 \\
\hline
\end{tabular}
important indicators to diagnose that a patient has intense pain. (F)

2. Pain level should be evaluated by healthcare personnel, not by the patient himself. (F)

3. A patient can sleep in spite of intense or mid-level pain. (T)

4. If the patient's attention can be drawn in another direction, it means the patient does not have as high a pain level as $s /$ he has stated. (F)

5. Before a pain relief method is applied, the patient should be encouraged to endure to pain as much as possible. (F)

6. If a patient's pain eases with placebo (sterile water injection), the pain is not real. (F)

7. Because the neurological system in children under two years of age is not completely developed, their pain sensitivity is low and their experience of pain is limited. (F)

8. Aspirin and other NSAl agents are not affective for chronic pain that stems from metastasis (F)

\begin{tabular}{|lll|l|l|l|l|} 
9. Non-pharmacological treatments (for & 33 & 25.2 & 98 & $\mathbf{7 4 . 8}$
\end{tabular} example heat application, music) are very effective for mid-level pain, but are not effective for serious pains. (F)

\begin{tabular}{|l|l|l|l|l|l|}
\hline 10. Respiratory depression rarely emerges in & $\mathbf{1 0 9}$ & $\mathbf{8 3 . 2}$ & 22 & 16.8
\end{tabular} patients who have been taking opioids for a long time (for months). ( $T$ )

\begin{tabular}{|l|l|l|l|l|}
\hline 11. Single analgesic agents should be used in & 59 & 45.0 & 72 & 55.0 \\
\hline
\end{tabular} a patient in pain rather than a combination of drugs. (F)

12. Sedative drugs are effective in reducing pain. (F)

\begin{tabular}{|l|l|l|l|l|l|}
\hline 13. Opioids should not be given to reduce & 31 & 23.7 & 100 & 76.3 \\
\hline
\end{tabular} pain to patients with a history of substance abuse, because these patients are at higher risk of repetitive addiction. (F)

\begin{tabular}{|l|l|l|l|l|}
\hline 14. The pain stated by children under the & 98 & $\mathbf{7 4 . 8}$ & 33 & 25.2 \\
\hline
\end{tabular} age of eleven should not be trusted. Nurses should trust parents about the pain level of the child. (F)

\begin{tabular}{|l|l|l|l|l|}
\hline $\begin{array}{l}\text { 15. It should be recommended to a patient } \\
\text { that non-pharmacological methods should } \\
\text { be used alone, not with pain medications. (F) }\end{array}$ & 62 & 47.3 & 69 & 52.7 \\
\hline $\begin{array}{l}\text { 16. Hot and cold applications should only be } \\
\text { applied to the painful area to be effective. (F) }\end{array}$ & 33 & 25.2 & 98 & $\mathbf{7 4 . 8}$ \\
\hline
\end{tabular}

*Percentages in Table 2 are valid for the nurses who answered the questions. NSAl: non-steroidal anti-inflammatory 
Table 3. Average pain management knowledge and attitude scores of the pediatric nurses $(n=131)$

\begin{tabular}{|lll|}
\hline Pain management knowledge and attitude scores & $\mathbf{n}$ & \% \\
\hline Low Level (1-5 points) & 47 & 35.9 \\
\hline Mid-Level (6-10 points) & 59 & 45.0 \\
\hline High Level (11 points and above) & 25 & 19.1 \\
\hline
\end{tabular}

The pediatric nurses taking part in the research were asked different questions to determine their clinical decisionmaking status. To the question 'which criteria do you use most while diagnosing the pain level of the patient?' $78.6 \%$ of the nurses answered 'I observe the patient's behavior', but $31.3 \%$ answered 'I ask the patient how much pain she/ he feels'. Most of the nurses (65.6\%) indicated that they used a pain scale when measuring patient's pain, and when they were asked whether they recorded their evaluations and diagnosis of the patient's pain, most of them $(87.8 \%)$ said they did. All the nurses (100\%) who indicated they recorded evaluations and diagnosis said that they recorded them on a nursing observation scale. The nurses taking part in the research reported that paracetamol (46.6\%), Non-Steroid Anti-Inflammatory Drugs (25.2\%), narcotics (20.6\%) and anesthetic analgesics (7.6\%) were the most widely used drugs in their clinics. Most of the nurses (87.8\%) stated that when giving medications which were ordered as in case of need', they gave the medication as they were ordered. 56.5\% of the nurses in the research reported that they had not been asked for a non-pharmacological method of pain relief for patients in pediatric clinics but $36.6 \%$ reported that they had been asked for 'cold application' and $26.7 \%$ reported that they had been asked for 'hot application'. Almost all of the pediatric nurses (99.2\%) reported that they get into contact with the patient's doctor about pain, and many of them (77.1\%) said that they reported changes in a patient's pain status. When asked 'Do you face any obstacles or problems in reducing or eliminating a patient's pain?', $58 \%$ of the nurses who participated in the research reported that they did, and they said that $29 \%$ of these problems were related to the 'patients' or their family's knowledge', $27.5 \%$ were related to 'doctors co-operation' and $23.7 \%$ were related to 'time'. To the question 'In which situations do you have to make a decision about a patient's pain?' $74.0 \%$ of the nurses answered 'identifying the patient's pain intensity', 55\% answered 'identifying a patient's pain' and $26.7 \%$ answered 'when medication is to be given to a patient'. When pediatric nurses were asked to place in order the professional/ethical dilemmas that they faced while stopping the patient's pain from the most important to the least important (1-9), 48.9\% of them stated that anxiety about respiratory depression was the most important dilemma for them, and $29.8 \%$ stated that conflict with the patient or the patient's family was the least important dilemma that they faced. When the nurses were asked at the end of the questionnaire to rank the first three issues about which they needed information related to pain management, they placed pain diagnosis in the first place (62.6\%), pharmacological pain management in the second place (35.9\%), and non-pharmacological treatments in the third place $(32.8 \%)$.

\subsection{Correlation Between Pediatric Nurses' Descriptive Characteristics and Their Total Mean Scores on Knowledge and Attitude About Pain Management}

When nurses' characteristics and their total mean scores on knowledge and attitude about pain management were compared, a statistically significant relationship was found between the education of the nurses, the unit where they worked and their total mean scores on knowledge and attitude about pain (respectively: Chi-Square=17.092, $\mathbf{p}=\mathbf{0 . 0 0 1}$, and Chi-Square=15.100, p=0.002) (Table 4). It was also found that the mean scores for knowledge and attitude about pain were higher for nurses who had a Master's Degree and worked at the Neonatal Intensive Care Unit (NICU). However, no statistically significant relationship was found between the ages, duties or years of work of the nurses and their total mean scores on knowledge and attitude about pain (respectively: Chi-Square $=7.949, p=0.093$; Chi-Square $=4.913$, $p=0.178$, and Chi-Square $=6.114, p=0.106)$. However, the total mean scores for knowledge and attitude of nurses who were in the 21-30 age group, who were working as Intensive Care Nurses and who had 6-10 years of working experience were higher than those of others (Table 4).

When considering the distribution of the units where pediatric nurses worked according to whether they used a pain scale to measure the patient's pain, it was found that $34.8 \%$ of the nurses using a pain scale worked in the Pediatric Units and $30.9 \%$ of them worked at the NICU. In the Chi-Square analysis it was found that there was a statistically significant difference between the groups $\left(X^{2}: \mathbf{1 4 . 6 9 5}, \mathbf{p}=\mathbf{0 . 0 0 2}\right.$ ) (Table 5).

When considering the distribution of the units where the pediatric nurses who were included in the research worked according to whether they recorded evaluations and diagnosis about pain, it was found that $46.5 \%$ of the nurses who recorded pain worked in the Pediatric Unit, and $41.3 \%$ of them worked at the NICU. A statistically significant difference was found according to the Chi-Square analysis between the nurses' recording patients' pain and the units where they worked ( $X^{2}$ : 33.706, $p=\mathbf{0 . 0 0 0}$ ) (Table 5). 
Table 4. Distribution of scores of knowledge and attitude about pain according to descriptive characteristics

\begin{tabular}{|c|c|c|c|c|c|}
\hline \multicolumn{2}{|c|}{ Descriptive characteristics } & $\mathbf{n}$ & $\begin{array}{c}\text { Pain } \\
\text { Knowledge } \\
\text { and Attitude } \\
\text { Score } \\
X \pm \text { SD }\end{array}$ & $x^{2}$ & $\mathbf{p}$ \\
\hline \multirow{5}{*}{ Age groups } & Less than 21 years & 4 & $4.50 \pm 2.08$ & \multirow{5}{*}{7.949} & \multirow{5}{*}{$p=0.093^{*}$} \\
\hline & $21-30$ years & 73 & $7.86 \pm 3.21$ & & \\
\hline & $31-40$ years & 48 & $7.00 \pm 3.19$ & & \\
\hline & $41-50$ years & 5 & $5.40 \pm 1.51$ & & \\
\hline & More than 50 years & 1 & $5.00 \pm 0.00$ & & \\
\hline \multirow{4}{*}{$\begin{array}{l}\text { Education } \\
\text { levels }\end{array}$} & $\begin{array}{l}\text { Health Vocational } \\
\text { High School }^{\mathrm{a}}\end{array}$ & 14 & $4.57 \pm 1.55$ & \multirow{4}{*}{17.092} & \multirow{4}{*}{$\begin{array}{c}\mathrm{p}=0.001^{*} \\
\mathrm{~b}=\mathrm{c}=\mathrm{d}>\mathrm{a} * *\end{array}$} \\
\hline & Associate Degree $^{b}$ & 14 & $6.92 \pm 3.31$ & & \\
\hline & Bachelor's Degree $^{c}$ & 91 & $7.53 \pm 3.06$ & & \\
\hline & Master's Degree $^{d}$ & 12 & $9.41 \pm 3.62$ & & \\
\hline \multirow{4}{*}{$\begin{array}{l}\text { Place of } \\
\text { work }\end{array}$} & Pediatric Unit ${ }^{a}$ & 53 & $7.52 \pm 2.83$ & \multirow{4}{*}{15.100} & \multirow{4}{*}{$\begin{array}{c}p=0.002^{*} \\
a=b=d>c^{* *}\end{array}$} \\
\hline & $\begin{array}{ll}\text { Pediatric Surgery } \\
\text { Unit }\end{array}$ & 14 & $7.07 \pm 2.40$ & & \\
\hline & $\begin{array}{l}\text { P e d i a t } r \text { i c } \\
\text { Emergency Unit }{ }^{c}\end{array}$ & 17 & $4.58 \pm 2.23$ & & \\
\hline & $\begin{array}{l}\text { Neonatal Intensive } \\
\text { Care Unit }^{d}\end{array}$ & 47 & $8.17 \pm 3.58$ & & \\
\hline \multirow{4}{*}{$\begin{array}{l}\text { Position/ } \\
\text { Duty }\end{array}$} & Clinical Nurse & 72 & $6.84 \pm 2.97$ & \multirow{4}{*}{4.913} & \multirow{4}{*}{$p=0.178^{*}$} \\
\hline & $\begin{array}{ll}\text { Intensive Care } \\
\text { Nurse }\end{array}$ & 43 & $8.34 \pm 3.52$ & & \\
\hline & Executive Nurse & 7 & $7.14 \pm 3.33$ & & \\
\hline & $\begin{array}{l}\text { Outpatient Clinic } \\
\text { Nurse }\end{array}$ & 9 & $6.44 \pm 2.35$ & & \\
\hline \multirow{4}{*}{$\begin{array}{l}\text { Years of } \\
\text { work }\end{array}$} & Less than 5 years & 45 & $7.42 \pm 3.51$ & \multirow{4}{*}{6.114} & \multirow{4}{*}{$p=0.106^{*}$} \\
\hline & $6-10$ years & 51 & $7.86 \pm 3.02$ & & \\
\hline & $11-15$ years & 20 & $7.05 \pm 3.21$ & & \\
\hline & More than 15 years & 15 & $5.60 \pm 2.19$ & & \\
\hline
\end{tabular}

*Kruskal-Wallis test, **Mann-Whitney $\cup$ test; $X \pm S D$ : mean \pm standard deviation

Table 5: Distribution of pediatric nurses by their use of a pain scale and their recording of pain according to the unit where they worked

\begin{tabular}{|c|c|c|c|c|c|c|}
\hline & $\begin{array}{l}\text { Pediatric } \\
\text { Unit }\end{array}$ & $\begin{array}{l}\text { Pediatric } \\
\text { Surgery } \\
\text { Unit }\end{array}$ & $\begin{array}{l}\text { Pediatric } \\
\text { Emergency } \\
\text { Unit }\end{array}$ & $\begin{array}{l}\text { Neonatal } \\
\text { Intensive } \\
\text { Care Unit }\end{array}$ & $x^{2}$ & p \\
\hline \multicolumn{7}{|l|}{ Pain Scale } \\
\hline Using $^{\mathrm{a}}$ & $34.8(42) \%$ & $9.2(8) \%$ & $11.2(5) \%$ & $30.9(31) \%$ & \multirow[t]{2}{*}{14.695} & $0.002^{*}$ \\
\hline Not Using ${ }^{b}$ & $18.2(11) \%$ & $4.8(6) \%$ & $5.8(12) \%$ & $16.1(16) \%$ & & $a>b$ \\
\hline \multicolumn{7}{|c|}{ Recording of Pain } \\
\hline Recording ${ }^{\mathrm{a}}$ & $46.5(51) \%$ & $12.3(11) \%$ & $14.9(8) \%$ & $41.3(45) \%$ & \multirow[t]{2}{*}{33.706} & \multirow[t]{2}{*}{$\begin{array}{c}0.000 * \\
a>b\end{array}$} \\
\hline $\begin{array}{l}\text { Not } \\
\text { Recording }\end{array}$ & $6.5(2) \%$ & $1.7(3) \%$ & $2.1(9) \%$ & $5.7(2) \%$ & & \\
\hline
\end{tabular}

*Pearson chi-square test

\section{DISCUSSION}

A life free of pain is the right of every child, and stopping the pain of children and improving their quality of life are the basic aims of nursing care (17). The quality of pain management is related to the knowledge, attitude and decision-making abilities of health care team members who carry out pain treatment $(6,12,18)$. Spending a longer time with patients provides an opportunity for nurses to observe a child's pain closely. However, whether nurses have the necessary knowledge, attitude and abilities to fulfill this role still remains unclear $(4,5,19)$.

In this study, in which pediatric nurses' knowledge, attitude and clinical decision-making abilities were studied, $69.5 \%$ of the nurses stated that in diagnosing the patient's intense pain, observed changes in vital signs are important indicators'. In a study by Demir et al. (13), it was found that the correct response rate to this question of nurses who worked at internal and surgical units was $7.2 \%$, but in research by Özer et al. (11) it was $8.5 \%$. The results and findings of the research were found to be quite low when compared with the results (88.4\%) of the research by McCaffery et al. (16).

Until the 1980s it was popular wisdom that in neonates, cortical functions, which play an important role in the interpretation and memory of painful experiences, were not fully developed $(8,20,21)$. Studies since that time have shown that a neonate can perceive and remember pain well, and feel pain from intrauterine life onwards (8). In the present study it was found that the response rate of correct answers to the question 'because the neurological system isn't completely developed in children under two years of age, pain sensitivity is low and pain experience is limited' was $48.9 \%$. These results were higher than the results (19.0\%) of research by Demir et al. (13), but they are lower than the results (61.3\%) of research by Özer et al. (11).

While evaluating pain it is important to choose the correct measurement tool according to an infant's features and the type of the pain to be evaluated $(22,23)$. In our study $65.6 \%$ of the nurses said they used a pain scale to measure the patient's pain. Nimbalkar et. al. (24) stated that they needed pain scales for assessing a neonate's pain (50\%). Demir et al. (13) reported that $66.7 \%$ of nurses did not use a scale to measure pain, and the proportion reported by Ay and Ecevit (25) was $67.7 \%$, and by Özer et al. (11) $74.5 \%$. Abdalrahim et al. (26) also stated that $95.7 \%$ of nurses did not use a scale to evaluate the patient's pain in the post-operative period. Efe et al. (9) also stated that one-half of the nurses (49.5\%) did not have knowledge about pain scales in pediatric surgical units. The main goals of nursing care are to relieve the pain of children and improve the quality of life. Pain diagnosis and control requires a team work. The nurse is one of the most important members of this team. The most important difference that distinguishes the nurse from other health care team members in pain management is that the nurses spend longer time with the patients and have the opportunity to monitor the child's pain more closely $(4,5,17,19)$. However, in our study and other studies, it was found that the necessary knowledge, attitude and clinical decisions-making abilities of pediatric nurses in fulfilling this role were not at the desired level. When the results are considered in general, it is seen that the rate of pain scale use is quite low. In the results of the 
statistical evaluation, a statistically significant difference was found between the use of a pain scale and the units where the nurses worked in favour of the Pediatric Unit and the NICU $\left(X^{2}: 14.695, p=0.002\right)$. This result is thought to be related to high level of knowledge and skills of Pediatric Unit and NICU nurses in using pain scales and objective evaluation of pain. According to the results obtained from the study, the mean scores on knowledge and attitude about pain management of most of the pediatric nurses were at mid-level (45\%), but a large number of pediatric nurses were at low-level (35.9\%). The results of the study resemble the results of Demir et al. (13), Özer et al. (11), McMillan et al. (14) and Nimbalkar et al. (24). It is thought that these results stem from nurses not having sufficient knowledge of pain physiology, and of the pharmacological and non-pharmacological management of pain. According to the statistical analysis results, there was a statistically significant relation between the nurses' educational background and the unit where they worked and their mean scores on knowledge and attitude about pain in favour of the nurses who had a Master's Degree and who worked at the NICU.

It was seen that the results of previous studies about nurses' recording of pain were different from one another. The rate of nurses' recording of pain in work by Demir et al. (13) was $88.9 \%$, and in a study by Özer et al (11) it was $71.5 \%$. In a study of nurses' care of patients in the post-operative period by Abdalrahim et al. (26), it was seen that there was no data on pain in the records of $35 \%$ of nurses. In our study, it was seen that the rate of recording by pediatric nurses was $87.8 \%$. It was found in the statistical evaluation that there was a statistically significant difference between the nurses' recording of pain and the units where they worked in favour of the Pediatric Unit (46.5\%) and the NICU (41.3\%). The lowest recording rate was in the Pediatric Surgery Unit (12.3\%). This was interpreted as being because nurses take post-operative pain experience as normal so they don't see the need to use a pain scale, and therefore the rate of recording is low.

This is supported by studies showing that in pain management, especially in pediatric patient groups, non-pharmacological methods are used in addition to pharmacological methods $(8,9)$. In our study it was found that non-pharmacological methods were used by pediatric nurses at a rate of $56.5 \%$. In the study by Demir et al. (13), it was found that $40 \%$ of nurses used non-pharmacological methods. In the study by Ay and Ecevit (25), it was found that nurses informed patients more frequently about medicines, observing the side effects of treatment and following up the vital signs and the effects of the illness and the medicine; and they seldom preferred non-pharmacological methods such as teaching, applying relaxation techniques and massaging. It was thought that nurses and doctors preferred pharmacological methods because they were easy to apply and showed their effects quickly. This opinion is supported by studies (27).

In the literature review, it was seen that nurses are inadequate in pain diagnosis and pain management, critical decision-making, choosing analgesics and knowledge of medicines $(11,28,29)$. In the present study it was found that when pediatric nurses were asked to rank the three most important issues that they needed to know concerning pain management, they stated 'pain diagnosis, pharmacological pain management and non-pharmacological treatments'. With its developing scientific knowledge content, nursing is in a position to solve the professional and ethical problems specific to its working area. In our study, when pediatric nurses were asked to order the professional and ethical dilemmas that they faced while stopping the pain of a patient from the most important one to the least important one, they stated that the anxiety they faced with regard to respiratory depression was the most important dilemma (48.9\%), and conflict with the patient and the family of the patient was the least important one (29.8\%). In the study by Demir et al. (13), the most important professional and ethical dilemma that nurses faced was overdosing and addiction; in a study by Karakaya (30) it was fear of patients becoming addicted. In the light of these findings, it is important for hospital administrators to start in-service training programmes on pain diagnosis, pharmacological management of pain and non-pharmacological treatments for pain, and the choice of a suitable pain scale for child age groups and clinical diagnosis, and it is also important to maintain these programmes.

\section{Study Limitations}

The study data was collected from a sample of pediatric nurses who were employed at pediatric clinics of a university hospital and a state hospital in Manisa, Turkey. These two hospitals have different opportunities, and different patient and staff profiles. In this research, nurses with a bachelor's and master's degree level of education mostly worked at the university hospital, while the nurses with a health vocational high school and associate degree level of education mostly worked at the state hospital. Therefore, the findings represent only this population and cannot not be generalized to all pediatric nurses.

\section{CONCLUSION}

As a result of the study, it was found that pediatric nurses had a mid-level of knowledge and behavior score related to pain management and had sufficient knowledge about pain diagnosis and management. However, it was found that the necessary knowledge, attitude and clinical decisions-making abilities of pediatric nurses for pain management were not at the desired level.

Acknowledgements: The authors wish to thank all pediatric nurses for participating in this study.

\section{REFERENCES}

[1] Kyle T. Essentials of Pediatric Nursing. 1st ed. Philadelphia: Lippincott Williams \& Wilkins; 2008.

[2] Walden M. Pain assessment and management. Verklan MT, Walden $\mathrm{M}$, editors. Core Curriculum for Neonatal Intensive 
Care Nursing. 4th ed. Missouri: Saunders Elsevier; 2010. p.333-345.

[3] Aslan EF, Bahadır A. Pain control reality: Nurses' knowledge and beliefs about the nature of the pain, evaluation of the pain and stopping the pain. The Journal of The Turkish Society of Algology 2005; 17: 44-51 (In Turkish).

[4] Ekim A, Ocakcı AF. Knowledge and attitudes regarding pain management of pediatric nurses in Turkey. Pain Manag Nurs 2013; 14: 262-267.

[5] Plaisance L, Logan C. Nursing students' knowledge and attitudes regarding pain. Pain Manag Nurs 2006; 7: 167-175.

[6] Kılıç M, Öztunç $G$. The methods used in pain control and the role of the nurse. F U Journal of Health Sciences 2012; 7: 3551 (In Turkish).

[7] Törüner EK, Büyükgönenç L. Pain management in children. Törüner EK, Büyükgönenç L, editors. Child Health Basic Nursing Approaches. 1st ed. Ankara: Göktuğ Publishing; 2012. p. 146 171 (In Turkish).

[8] Derebent E, Yiğit R. Pain in neonatal: evaluation and management. Journal of Cumhuriyet University School of Nursing 2006; 10: 41-48 (In Turkish).

[9] Efe E, Dikmen Ş, Altaş N, Boneval C. Turkish pediatric surgical nurses' knowledge and attitudes regarding pain assessment and nonpharmacological and environmental methods in newborns' pain relief. Pain Manag Nurs 2013; 14: 343-350.

[10] Kennedy RM, Luhmann J, Zempsky WT. Clinical implications of unmanaged needle-insertion pain and distress in children. Pediatrics 2008; 122: 130-133.

[11] Özer S, Akyürek B, Başbakkal Z. Studying nurses' knowledge, attitude and clinical decision-making abilities about pain. The Journal of The Turkish Society of Algology 2006; 18: 36-43 (In Turkish).

[12] Cöçelli LP, Bacaksız BD, Ovayolu N. The role of the nurse in pain treatment. Gaziantep Medical Journal 2008; 14: 53-58 (In Turkish).

[13] Demir DY, Yıldırım Usta Y, İnce K, Türken Gel K, Akı Kaya M. Determining of nurses' knowledge, behavior and clinical decision making regarding pain management. J Contemp Med 2012; 2: 162-172 (In Turkish).

[14] McMillan SC, Tittle M, Hagan S, Laughlin J, Tabler RE. Knowledge and attitudes of nurses in veterans hospitals about pain management in patients with cancer. Oncol Nurs Forum 2000; 27: 1415-1423.

[15] Ferrell B, McCaffery M. Knowledge and attitudes survey regarding pain. (Accessed: 2014 February 4). Available from: https://prc.coh.org/Knowldege\%20\%20\&\%20Attitude\%20 Survey\%207-14\%20(1).pdf.

[16] McCaffery M, Robinson ES. Pain. Here's how you respond. Nursing 2002; 32: 37-47.
[17] Elçigil A. Factors affecting pediatric nurse's decision-making in child's pain management. Journal of Dokuz Eylul University School of Nursing 2011; 4: 48-53 (In Turkish).

[18] Yilmaz F. The Effects of Different Treatments, Applied to Neonatal Who Have Had a Painful Procedure, on Duration of Crying and Pain. Ataturk University. Institute of Health Sciences, PhD Thesis. 2008 (In Turkish)

[19] Rond MEJ, Wit R, Van Dam FSAM, Campen BTM, Hartog YM, Klievink RMA. A pain monitoring program for nurses: Effects on nurses' pain knowledge and attitude. J Pain and Symptom Manage 2000; 19: 457-467.

[20] Dinçer Ş, Yurtçu M, Günel E. Pain in Newborns and nonpharmacologic treatment procedures. Selcuk University Medical Journal 2011; 27: 46-51 (In Turkish).

[21] Ovalı F. Preventing pain in the newborn. Dağoğlu T, Görak G, editors. Basic Neonatalogy and Nursing Principles. İstanbul: Nobel Medical Bookstores; 2008, p. 726-732 (In Turkish)

[22] Cignacco E, Hamers JP, Stoffel L, Van Lingen RA, Gessler P, McDougall J, Nelle M. The efficacy of non-pharmacological interventions in the management of procedural pain in preterm and term neonates: A systematic literature review. Eur J Pain 2007; 11: 139-152.

[23] Çelebioğlu A, Polat S. Pain evaluation in neonatal. Syndrome 2004; 16: 99-101 (In Turkish).

[24] Nimbalkar AS, Dongara AR, Phatak AG, Nimbalkar SM. Knowledge and attitudes regarding neonatal pain among nursing staff of pediatric department: An Indian experience. Pain Manag Nurs 2014; 15: 69-75.

[25] Ay F, Ecevit AŞ. Post-operative pain and nursing practices. The Journal of The Turkish Society of Algology 2010; 22: 21-29 (In Turkish).

[26] Abdalrahim MS, Majalı SA, Bergbom I. Documentation of postoperative pain by nurses in surgical wards. Acute Pain 2008; 10: 73-81.

[27] Yılmaz M, Gürler H. Nursing approaches to post-operative pain of patients: Patients' opinions. The Journal of The Turkish Society of Algology 2011; 23: $71-79$ (In Turkish).

[28] Mackintosh C, Bowless S. The effect of an acute pain service on nurses knowledge and beliefs about post-operative pain. J Clin Nurs 2000; 9: 119-126.

[29] Bacaksiz BB, Pirbudak Cöçelli L, Ovayolu N, Özgür S. The evaluation of interventions for pain control done by health staff caring the patient. The Journal of The Turkish Society of Algology 2008; 20: 26-36 (In Turkish).

[30] Karakaya A. Determination of Attitudes of Healthcare Professionals Towards Opioid Use. Eskişehir Osmangazi University. Institute of Health Sciences, MSc Thesis. 2007. (In Turkish). 